\title{
Research on Innovative Design Method Based on TRIZ_-Taking the Elderly-Oriented Transformation of Outdoor Seats as an Example
}

\author{
Zhang Peng ${ }^{1}$, Haiyong Shen ${ }^{2}$ and Yang Tao ${ }^{1 *}$ \\ ${ }^{1}$ School of Design and Art,, Shenyang Jianzhu University, Shenyang City, Province,110168, China \\ ${ }^{2}$ School of Design and Art,, Shenyang Jianzhu University, Shenyang City, Province, 110168, China
}

\begin{abstract}
This article takes the aging modification of outdoor seats as an example to analyze and discuss the application of TRIZ in the innovative design process. According to this method, the analysis model is constructed and imported into TRIZ tool for solutions, and finally a preliminary design plan and a series of optimization plans are quickly obtained, after analysis and comparison, the final plan was determined, which verified the obvious advantages of the comprehensive application method of TRIZ and innovative design. It can effectively break the mindset, improve the quality and innovation of the design, provide a more efficient and systematic innovation model for the design, and greatly shorten the time required for the design process, combined with the current situation and trend of aging in China, it also provides new theories, new ideas, and new perspectives for future suitable aging design.
\end{abstract}

\section{TRIZ design overview}

The naming of TRIZ is an acronym for Russian transliteration of "Teoriya Resheniya Izobreatatelskikh Zadatch" in English, , the Chinese translation is "inventive problem solving theory",which is a set of innovative thinking based on the analysis of more than 2 million high-level invention patents in various countries around the world built in the 1950s by the former Soviet scientist and patent researcher Genrich Altshuller and the team he leads, is also an innovative invention problem-solving method system with methodology and a large number of analytical tools integrated. All the views of TRIZ theory are based on the Technology System Development Evolution Model it summarized, and it has now formed a complete theoretical system from innovative thinking, analytical tools to comprehensive multidisciplinary principles and principles problem solving tools after decades of development and improvement. With its good maneuverability and scientific analysis tools, it has a pivotal position in the field of innovation research around the world, which is recognized as an efficient innovation theory and has outstanding effects in solving innovation problems in multiple industries.
TRIZ theory believes that all the innovation processes can be summarized as a few innovation principles and strategies. Therefore, the innovation in the design field is also an activity that follows certain innovative principles and methods. Its main contents concludes nine core contents of the eight rules of technological system evolution, IFR(ideal final result) , 40 innovative principles, the Altshuller contradiction matrix, the four separation principles, 76 standard solutions, the substance-field analysis model, the ARIZ standard algorithm and the scientific principles base."The main steps of using TRIZ theory to carry out innovation activities are to convert actual problems into TRIZ standard problems, import into the analytical tools provided by TRIZ to draw out the possible standardized solutions, and transform these solutions to form feasible final solutions" [1] Compared with traditional innovation methods such as "brainstorming method" and "trial and error method", TRIZ has the advantages of strong target orientation, clear and orderly steps, and rich tool systems, which can avoid a lot of trial and error costs and time consumption caused by relying on experience and disordered thinking, and improve the efficiency and quality of innovation activities (Figure 1). 


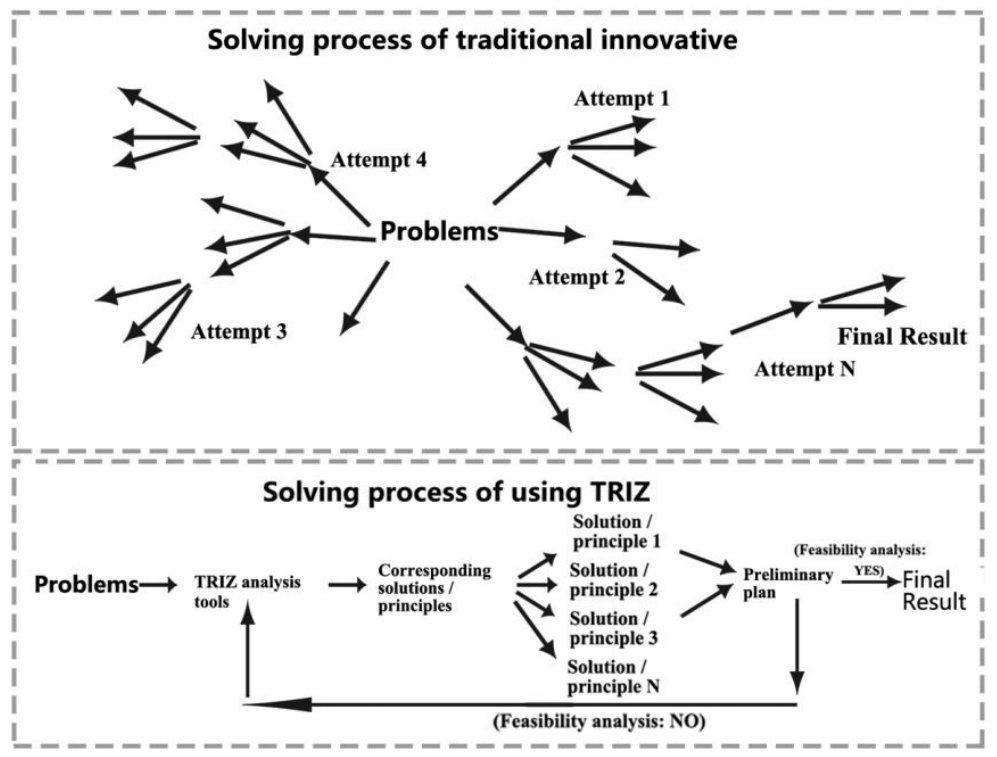

Figure1. Comparison of traditional innovation methods and TRIZ

(Source: self-drawn by the author)

Generally speaking, it is to try 10 to 100 times to find a solution when facing with relatively simple problems in the design process, and it is to try thousands of times or take up to several months or even several years when facing with relatively complex problems. If the TRIZ are taken to find the most effective way, the number of attempts can be reduced to $1 / 1000 \sim 1 / 10$, accordingly, the time required to generate these solutions will be reduced.[2] The TRIZ theory is currently adopted by well-known companies in more than 30 countries such as the United States and Germany. For example, Mercedes-Benz and Siemens have set up a TRIZ theoretical research department to guide the design, production and sales of various links, and provide a solid method and theoretical basis for ensuring efficient and stable innovation results. After introducing the TRIZ theory in 1998, Samsung Advanced Technology Research Institute of South Korea solved a large number of product innovation problems for the company, and there are more than 1,000 authorized invention patents derived from this.[3]

The research of TRIZ theory in China is relatively late. It has only been more than 30 years since its introduction and not been valued by experts and scholars at the beginning, so its development has been slow. At present, the existing research results are mainly concentrated on the transformation and promotion of new technologies. There are few achievements which use the innovation of TRIZ theory from in-depth research on design methods from the perspective of innovative design. There are currently many problems in the design of outdoor activity facilities such as rest seats which has the problems like the designs that do not take into account the needs of the elderly, insufficient physical comfort of the facilities and usage characteristics that are greatly affected by the weather, etc. In order to improve the functions of environmental facilities and enhance the experience of elderly users, this article will take the rest seats as an example to make appropriate elderly-oriented transformation. Introducing TRIZ theory into its design process can provide a powerful analysis tool for design problems, quickly and effectively eliminate product characteristic conflicts during the elderly-oriented process, and improve design efficiency and effectiveness. And from this, a set of outdoor environmental facility innovation facility methods based on TRIZ theory is proposed to verify the feasibility of TRIZ theory for innovative design activities.

\section{Investigation and analysis of the current elderly-oriented status of seats in residential parks}

When people are conducting outdoors activities, sitting is one of the most important behaviors. Most of the time, the ratio of the number of sitting people to the total number of people will reach $50 \sim 80 \%$. Willam.H. Whyte proposed that the most popular squares tend to have more sitting space. When assessing the quality of the public environment in a specific area, whether providing more and better conditions for people to sit must be taken as the most important factor.

In the 1980s, North American disabled architect Ronald Meyes proposed the concept of "universal design", which extended the user's consideration scope to the elderly, the disabled and other special groups. "Universal design" can be understood as a further expansion of barrier-free design and age-appropriate design. Its design principles mainly include seven principles:1. Anyone can use it equally. 2. Free height. 3. The method of use is easy to understand. 4. The necessary information can be understood immediately. 5 . Use fault tolerance. 6. Low physical burden. 7. Use space size.

At present, China has become the country with the most elderly population in the world. As early as 1999, 
China's population aged 60 years and over accounted for more than $10 \%$ of the total population and formally entered an aging society. According to data from the National Bureau of Statistics, as of the end of 2019, the country 's population aged 60 and over was 254 million, accounting for $18.1 \%$, of which the population aged 65 and over reached 176 million. The problem of population aging is becoming more and more serious. China's pension service system is not yet perfect, and there is a large gap in social pension service. $90 \%$ of the total supply of pension service is home-based pension service.[4] At the present stage, home-based pension service is still the most typical and common way of pension service in China. The aging of the population poses a huge challenge to the elderly-oriented part of the residential community infrastructure in China.

The elderly-oriented design is based on the needs of the elderly, the behavior and life needs of the elderly should be considered as fully as possible in the design process. Applicable objects of public facilities in the community should include but not limited to the elderly. "Therefore, the principles of universal design should be followed in its design to carry out the elderly-oriented design that does not affect other users, so that the design can be adapted to the community residents' all-age."[5]

Field interviews and questionnaire surveys were used to investigate and analyze the needs for use of rest seats in the community for the 320 elderly people over the age of 60 in three elderly communities in Shenyang.

From a physiological point of view, elderly people's physical function is reduced and they are easily fatigued. They often need to take a short break during outdoor activities, or directly switch to meditation, talking and other activities, etc. therefore, they use the rest seating facilities in the community more frequently. According to the survey, more than $90 \%$ of the elderly said that they use rest seats multiple times a week during outdoor activities and they believe that safety and health are the areas where rest seat facilities need to be regulated and guaranteed most. As the elderly's physical resistance and immunity decline, they generally pay more attention to the safety and hygiene of public rest seats. In addition, one of the most important factors determining the seatability of the seat is the physical comfort of the seat, The quality of seatability will directly affect the frequency of use for the elderly Therefore, the physical comfort of the rest seat is the focus of elderly-oriented design. Among the respondents, 271 elderly people believe that the current use of rest seat facilities in the community is not comfortable, accounting for $84.6 \%$. The problems reflected are mainly concentrated in the two aspects of the hard seat surface material and cold touch feeling in the cold weather. After inquiries, it is found that some of the elderly will use newspapers or bring their own cushions to solve such situations. In this process, problems such as forgetting to bring cushions or losing cushions often occur, which brings great inconvenience to the elderly's outdoor activities. Moreover, it takes longer for the elderly to accept new things. In the survey, $75.9 \%$ of the elderly hope that the function of the rest seat should be as simple and understandable as possible to reduce the difficulty of operation and learning.

From a psychological point of view, the physical strength and sense of security of the elderly decline,.Therefore, whether the rest seat is convenient can directly affect the utilization rate of the rest seats. The elderly's living environment and interpersonal relationship change greatly after retirement, and the chances of interacting with others are reduced, the emotional loss, mental state deterioration are easy to occur. "In order to adapt to this change, the elderly are eager to stay in touch and communicate with relatives, friends or neighbors."[6] The resting seats grouping arrangement in the park can provide convenient conditions for social activities, greatly promote the generation of this connection and interaction, and alleviate possible negative emotions to a certain extent. A total of 275 elderly people in the survey hope that the seating arrangement will be more concentrated, so as to facilitate conversation with people or group activities, which accounts for $85.9 \%$ of the total number of respondents. In addition, in addition to talking with people, the elderly people who sit are often accompanied by activities such as watching others or enjoying the scenery. Facing with such demands, the seats should be coordinated with the environment as much as possible, and actively integrated into the surrounding environment. It is necessary to pay attention to the orientation and vision when arranging, to improve the possibility of interaction between the elderly and the environment.

In addition, as a community public facility, the planning, procurement, installation and maintenance of outdoor rest seats are the responsibility of the community. The community's opinions and suggestions on elderly-oriented rest seats are also an important part of user needs. It can be learned from interviews with many community leaders that considering the operation costs of the community, most communities often consider the two aspects of the cost and post-maintenance investment on seats selection. Therefore, elderly-oriented transformation should reduce the cost and the difficulty of later maintenance on the basis of meeting the needs of the elderly.

According to the demand survey, it can be concluded that the demand and proportion of the elderly rest seat use (Figure 2) 


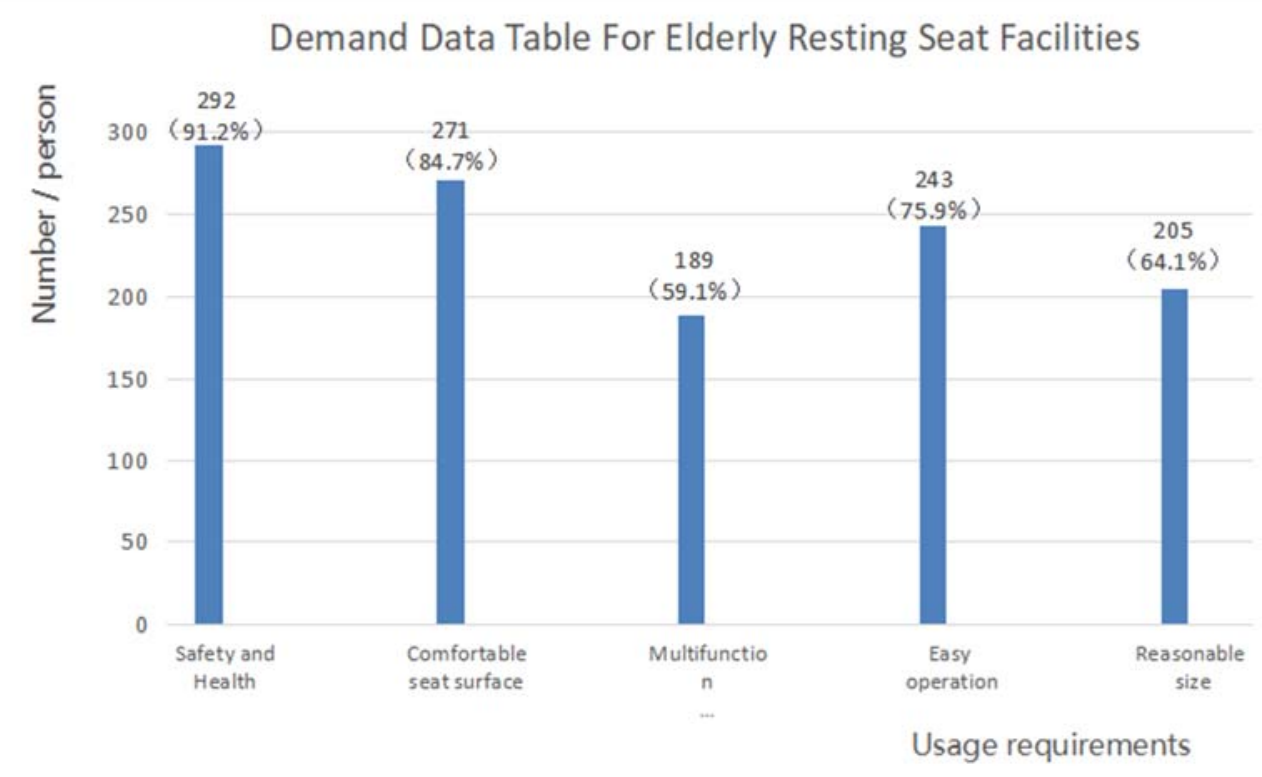

Figure 2. Demand data table for elderly resting seat facilities(Source: self-drawn by the author)

It can be drawn from the results of data collation that in terms of physical comfort of the seat, the elderly pay more attention to "safety and hygiene", "seat comfort" and "ease of use". In turn, it can be determined that the elderly-oriented design should meet the characteristics of the product demand first to achieve a guiding role in the innovative design process.

\section{Innovative design of rest seats in residential parks based on TRIZ theory}

The elderly mainly carry out activities such as walking, reading, napping, playing chess, sunbathing, talking, etc. in the outdoor environment, at the time they often need to use environmental facilities with corresponding functions. Because the elderly generally suffer from decreased physical function and are prone to fatigue, the use of rest seats is frequent. However, after investigation and investigation, it is found that the public seats in the elderly community in China currently have problems such as hard seat surfaces and cold touch, which can not meet the needs of elderly people with weak constitutions to relax or rest for a long time, the chair surface is often dirty due to dust, and it cannot be seated. Moreover, the seat size is not suitable for the elderly in the park.

Based on the needs of the elderly, this chapter optimizes the innovative designs the rest seats in the residential park, uses the innovative tools provided by the TRIZ theory for analysis and solution, and Propose a set of TRIZ application processes suitable for environmental facility design to demonstrate the feasibility of TRIZ theory applied to the field of environmental facility design.

\subsection{The application process of TRIZ innovation theory in the design of this case}

According to the theory of TRIZ system evolution, the innovative and optimized design of outdoor rest seats is the process of improving the ideality of the system and reducing the gap between reality and the final ideal. As an environmental facility for people to use, the improvement of the ideality of the rest seat mainly comes from whether the needs of users are metor not. There are three aspects of providing sufficient sitting space, physical comfort of the seat and the layout of the seat in improving the comfort of sitting behavior. This article mainly conducts the analysis from the perspective of improving the physical comfort of the seats, That is to improve the related technical characteristics of the ergonomic material and texture of the resting seats.

According to the survey results of the functional needs of the elderly group, combined with the technical characteristics of the rest seats, this case first builds a comprehensive quality house which can perform substance-field analysis directly according to product characteristics and functional requirements to improve the deficiencies of the system, finally, this case also lists the negative correlation characteristics according to the product characteristic matrix at the top of the quality house model, and converts them into corresponding general engineering parameters and imports them into the TRIZ analysis tool. If the type of contradiction between the characteristics is the technical contradiction, the Altshuller matrix will be used to find the corresponding invention principle, while if it is the physical contradiction, the four separation principles are used to find the invention principle. Finally, the standard solution or the principle of invention will be transformed into an implementable innovative solution, and the feasibility analysis of the results will be carried out. If feasible, the final solution can be obtained. If there are other problems that need to be optimized in the solution, the solution will be returned to the house of quality model for feedback to eliminate the product characteristic conflict that hinders the feasibility of the solution until the final solution is obtained(Figure 3) 


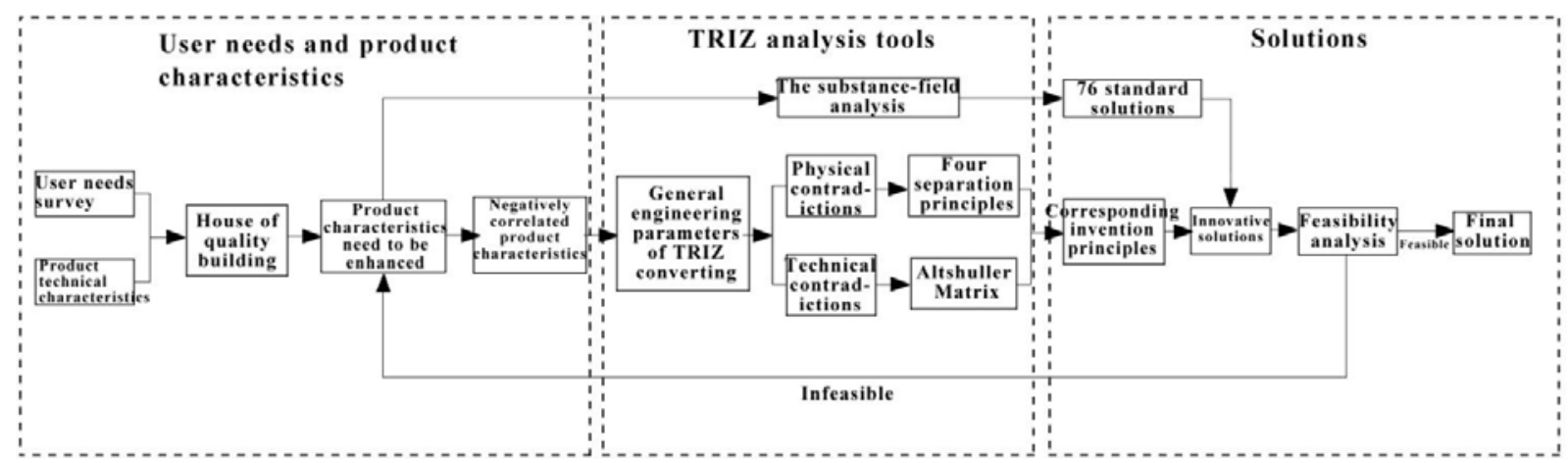

Figure 3. The application process of TRIZ in this case design(Source: self-drawn by the author)

\subsection{Comprehensive quality house model building}

The purpose of building a comprehensive quality house is to further confirm the performance of the product to be optimized by analyzing the correlation between product characteristics and user needs (Figure 4). According to the needs, it is to research data and related characteristics, to list the house of quality matrix, and to use different symbols to distinguish the degree of correlation between the spaces in the figure. The "-" symbol in the quality roof indicates that there is a negative correlation between product characteristics, that is to improve one of the product characteristics will cause the deterioration of another characteristic. It can be seen from the house of quality that there are two product characteristics including the material comfort and the shape of the seat surface strongly related to the need to improve the comfort of the seat surface. Among them, improving material comfort often leads to a decrease in material strength and weather resistance. At present, most of the rest seats of the community in our country are made of metal or anti-corrosion wood. The seats are hard and cannot be used after rain and snow weather and in winter for a long time, which is difficult to meet the requirements of the elderly in the community for the comfort of the rest seats. If it is replaced with a soft material chair surface with high comfort, the outdoor weather resistance is generally worse than that of metal or anti-corrosion wood, and the problem of being unusable for a long time after rain and snow is also difficult to solve.

\subsection{Product characteristic conflict analysis and resolution}

After analyzing the requirements of the model of the quality house, meeting the reasonable size requirements will not produce product characteristic conflicts, which are the simple problems in the TRIZ problem difficulty classification and can be solved without importing the solution in the TRIZ conflict analysis tools. With the gradual increase of age, the elderly will have changes in body dimensions such as hunchback and height atrophy, which will affect the standard size of the elderly-oriented design. (Figure 5)

It is to convert the negative correlation characteristics of the comfort of the chair surface material into TRIZ general engineering parameters and import them into the TRIZ tool for analysis. (Figure 6) 


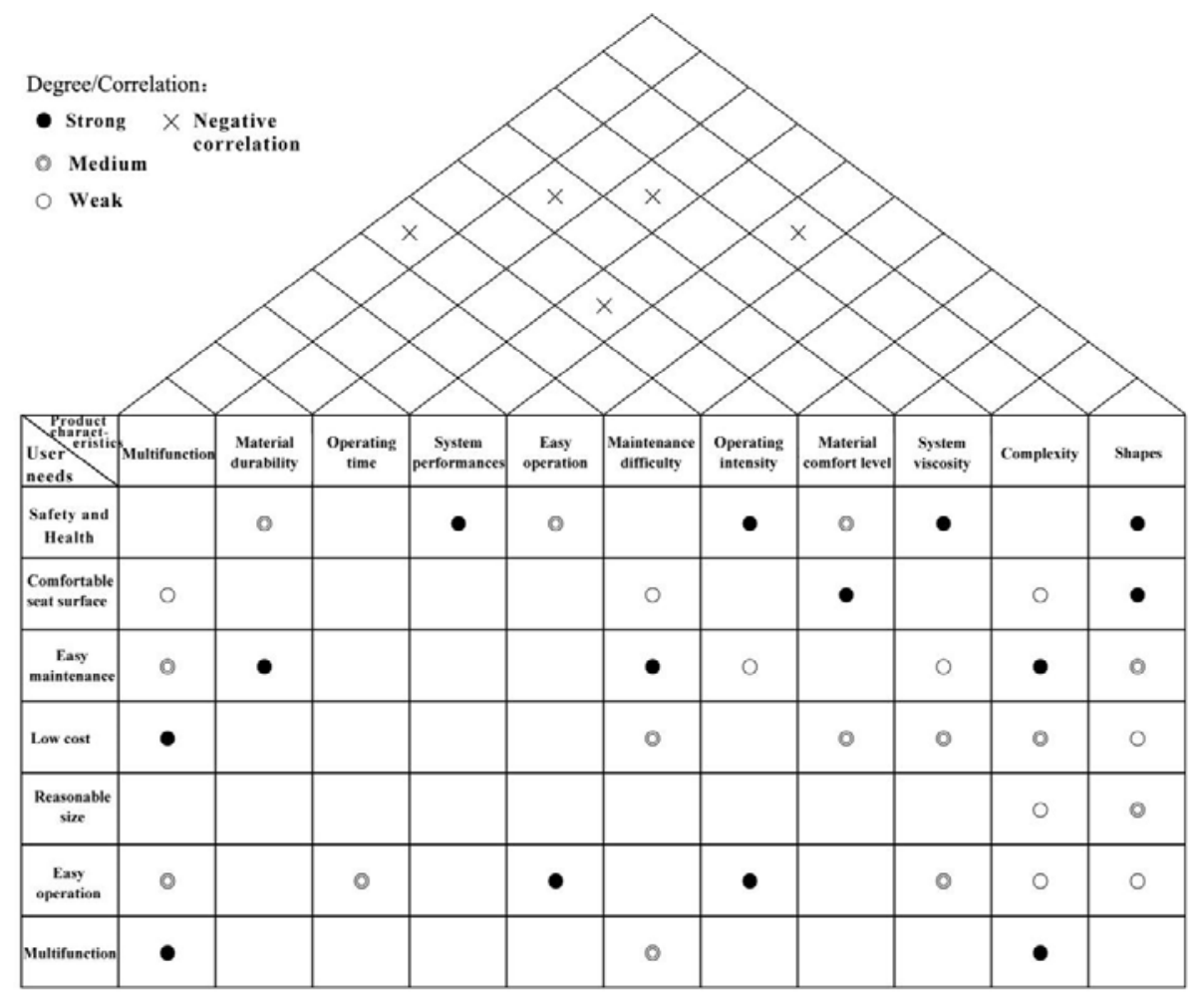

Figure 4. Comprehensive quality house model of rest seats for the elderly community (Source: self-drawn by the author)

\begin{tabular}{|l|l|}
\hline Seat height & $\begin{array}{l}450 \mathrm{~mm}-500 \mathrm{~mm} \text {, being too short will cause the elderly } \\
\text { to have more knee pressure when they get up }\end{array}$ \\
\hline Seat depth & $\begin{array}{l}400 \mathrm{~mm}-500 \mathrm{~mm} \text {, being too deep will cause the old man to } \\
\text { struggle when they get up }\end{array}$ \\
\hline Armrest & $\begin{array}{l}\text { it is generally } 200 \mathrm{~mm}-250 \mathrm{~mm} \text { higher than the chair surface, } \\
\text { it is best to make it reach forward for easy grip. }\end{array}$ \\
\hline Backrest & slightly harder material is needed to provide some support. \\
\hline Load limit & less than $120 \mathrm{KG}$ per person \\
\hline
\end{tabular}

Figure 5. Design standards for elderly-oriented seats (Source: author's self-drawn with data referring to the national building standard design atlas "Old People's Residential Building")

\begin{tabular}{|c|c|c|c|c|}
\hline No. & Contradiction & Contradiction description & General engineering parameters & $\begin{array}{c}\text { Corresponding common } \\
\text { solutions } \\
\end{array}$ \\
\hline 1 & $\begin{array}{c}\text { Technical } \\
\text { contradiction }\end{array}$ & $\begin{array}{l}\text { Improvement of hardness and thermal conductivity of bench } \\
\text { seat surface and deterioration of material strength and } \\
\text { outdoor durability }\end{array}$ & $\begin{array}{l}\text { Parameters Improving: } \\
\text { 31. Objects produce harniful } \\
\text { factors } \\
\text { Degradation parameters: } \\
\text { 14. Strength and durability }\end{array}$ & $\begin{array}{c}\text { NO.15 dynamic } \\
\text { NO.35 physical / chemical state } \\
\text { changes } \\
\text { NO.22 turning harm into benefits } \\
\text { NO.2 extraction }\end{array}$ \\
\hline
\end{tabular}

Figure 6. TRIZ contradiction analysis and invention principle (Source: self-drawn by the author)

This type of contradiction is a technical contradiction. Improving product characteristics can be translated into No. 31 General Engineering Parameters, that is the objects produce harmful factors, the characteristics of degraded products can be converted into No. 14 engineering parameters, that is the strength. The corresponding invention principles provided by the contradiction matrix are NO.15 dynamic, NO.35 chemical state changes, NO.22 turning harm into benefits, and NO.2 extraction. The invention principles NO.15, 
NO.35, and NO.22 can be converted into solutions for this solution.

NO.15 Dynamic: It is to make the seat surface reversible, and add a traction spring at the turning axis. It can flip the chair surface to the use position when using, When it is not at use, the chair surface will automatically turn back to the down-tilt state to prevent the chair surface from being exposed to the sun and rain to improve the weather resistance of the material in the

NO.22 Turning Harm into Benefits: The original chair surface materials are the materials such as metal and wood with high hardness and strength, which are the harmful feature for the comfort of the chair surface. outdoor environment, and to avoid the impact of dust and snow.

NO.35 Physical / Chemical Changes: The soft material of the seat surface can choose a film material with better weather resistance or a layer of better weather resistance on the surface, such as neoprene, aluminum film composite materials such as aluminum film EVA foam material or aluminum film pearl cotton, etc. to improve the durability of the material. (Figure 7)

To sum up, the initial plan is to design the automatic flip-type chair surface, to apply moisture-proof and weather-resistant treatment to soft surface materials, use anti-corrosion wood material for the basic stress structure.(Figure 8)

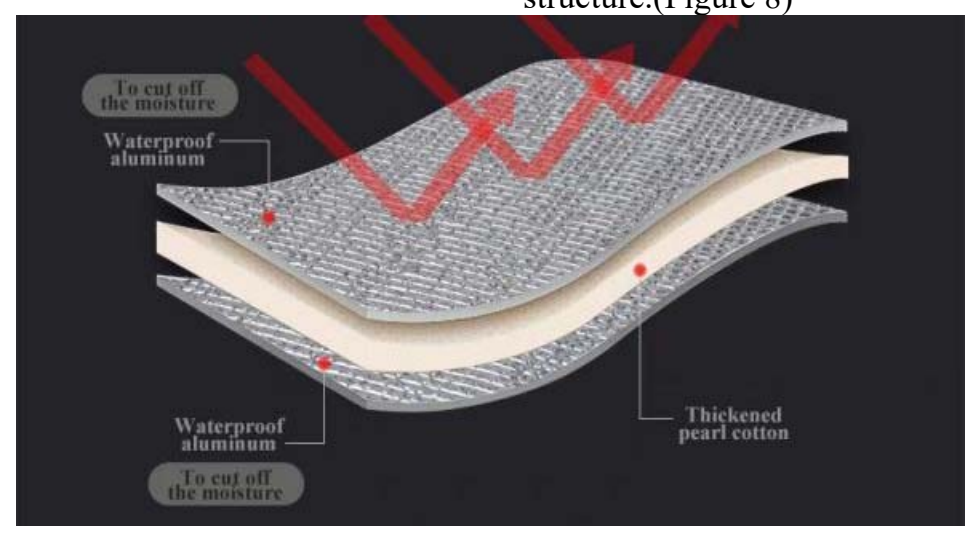

Figure 7. Aluminum film pearl cotton composite material (Source:from the network)
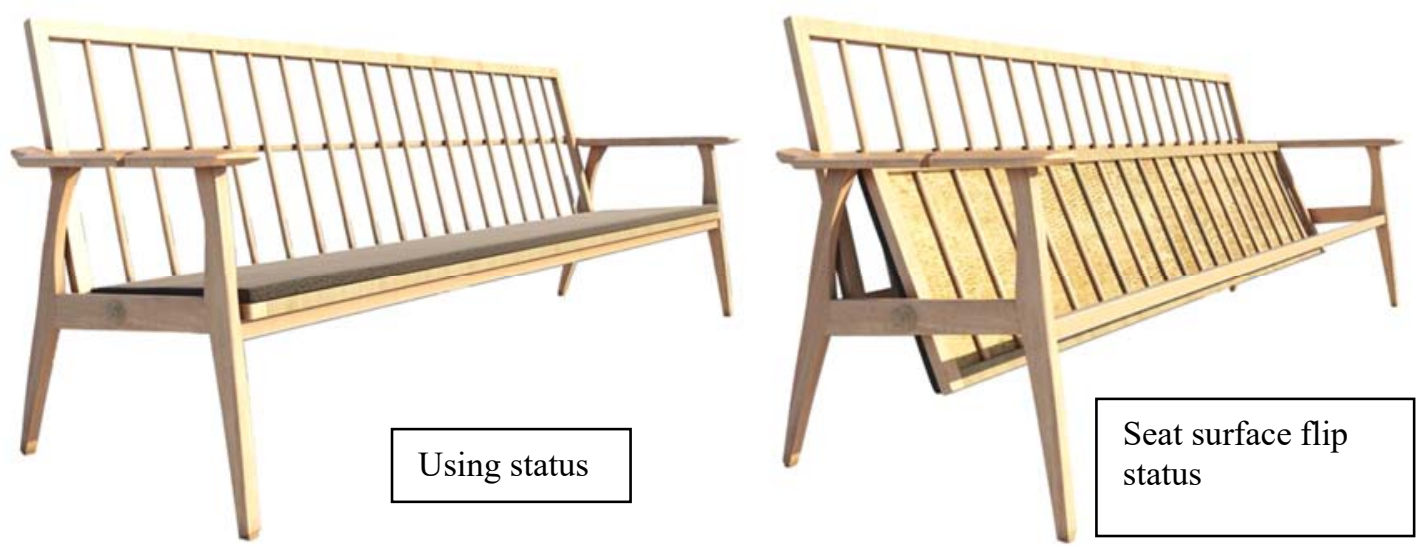

Figure 8. Preliminary plan model (Source: author's self-drawn)

\subsection{Preliminary plan optimization}

After feasibility analysis, it was found that the preliminary plan still has problems to be optimized, which can be converted into TRIZ standard. There are two pairs of technical contradictions and two pairs of physical contradictions in the Preliminary plan optimization.(Figure 9) 


\begin{tabular}{|c|c|c|c|c|c|}
\hline No. & Contradiction Type & Contradiction description & General eng & gineering parameters & $\begin{array}{c}\text { Corresponding common } \\
\text { solutions }\end{array}$ \\
\hline 2 & $\begin{array}{l}\text { Technical } \\
\text { contradiction }\end{array}$ & $\begin{array}{l}\text { Elderly people's operation difficulty decreases and } \\
\text { system complexity deteriorates }\end{array}$ & $\begin{array}{r}\text { Paramg } \\
\text { 33. } \\
\text { Degrad } \\
\text { 36. De }\end{array}$ & $\begin{array}{l}\text { neters Improving: } \\
\text { 3.Operablity } \\
\text { dation parameters: } \\
\text { device complexity }\end{array}$ & $\begin{array}{c}\text { NO.32 color changes } \\
\text { NO.26 Copy } \\
\text { NO.12Equipotentiality principle } \\
\text { NO.17 Dimension changes }\end{array}$ \\
\hline 3 & $\begin{array}{c}\text { Technical } \\
\text { contradiction }\end{array}$ & $\begin{array}{l}\text { Increased Elderly-Oriented functions and } \\
\text { increased difficulty in maintenance }\end{array}$ & $\begin{array}{l}\text { Param } \\
\text { 35. Adapt: } \\
\text { Degrad: } \\
\text { 34. } \mathrm{N}\end{array}$ & 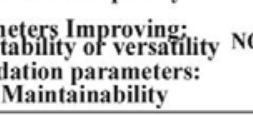 & $\begin{array}{c}\text { NO.1 Segmentation } \\
\text { NO.16 insufficient or excess action } \\
\text { NO.7 nesting } \\
\text { NO.4 asymmetry } \\
\end{array}$ \\
\hline No. & Contradiction Type & Contradiction description & & Separation principles & $\begin{array}{c}\text { Corresponding common } \\
\text { solutions }\end{array}$ \\
\hline 4 & $\begin{array}{c}\text { Physical The elder } \\
\text { contradiction slowly, }\end{array}$ & $\begin{array}{l}\text { ly are slow to move and require the seat surface to flip back to the use su } \\
\text { that is, the resistance of the flip axis is large. Convenient operation requ } \\
\text { turnover, that is, the resistance of the turning shaft should be sma }\end{array}$ & $\begin{array}{l}\text { ce and rebound } \\
\text { flexible seat }\end{array}$ & Condition separation & $\begin{array}{l}1,7,25,27,5,22,23 \\
33,6,8,14,25,35,13\end{array}$ \\
\hline 5 & $\begin{array}{c}\text { Physical The ch } \\
\text { contradiction }\end{array}$ & $\begin{array}{l}\text { aracteristics of the flip spring determine that the greater the flip angle of the } \\
\text { st the operation.Elderly-Oriented design requires uniform and labor-saving o }\end{array}$ & $\begin{array}{l}\text { surface, the more } \\
\text { ttion in the process }\end{array}$ & Condition separation & $\begin{array}{l}1,7,25,27,5,22,23 \\
33,6,8,14,25,35,13\end{array}$ \\
\hline
\end{tabular}

Figure 9. TRIZ contradiction analysis and invention principle (Source: self-drawn by the author)

Contradiction number 2: (Improvement parameter: 33. operability Deterioration parameter:36. Device complexity)The operation of flipping the chair surface is too difficult for the elderly who are unable to bend over, while most of the devices capable of automatically turning over the chair surface are complicated in structure and expensive, which are not suitable for use in public rest seats. The corresponding invention principles of introducing contradictory parameters into the Altshuller matrix are: NO.32, NO.26, NO.12, NO.17. After analysis, the NO.12 Equipotentiality principle and the NO.17 dimension change principle can be used to solve the problem.

NO.12 Equipotentiality Principle: Elderly people who are unable to bend over due to mobility difficulties usually need to use crutches, Therefore, the crutch slots should be reserved at the armrest of the rest seats to facilitate the placement of the crutch.

In addition, the transmission rod that can rotate with the chair surface can be added to the structure, with the end connected to the crutches storage slot. Because the rear end of the crutch is pressed against the transmission rod, when operating, it is easy to turn the chair surface easily by grabing the upper rubber part and using the weight of the arm to press down slightly. In this way, indirect control with a simple mechanical device not only avoids the potential danger caused by the bending operation for the elderly, but also avoids the automation system causing the system to be too complicated. In addition, the items carried by the elderly are often placed next to the elderly to form a seat due to the lack of a special storage location, which reduces the seat usage rate. At this stage, the seat design of some parks has been improved in response to this situation, the practice is to make a protruding hook at both ends of the backrest. But this protruding hook is easy to cause harm to the elderly too. And the memory of the elderly is often poor, they have insufficient sense of security in the outdoor environment, psychologically they tend to keep their belongings within easy reach of their sight to prevent loss or forgetting. Therefore, the usage rate of this backrest hook is extremely low. In this case, the crutch storage slot protruding next to the armrest can not only store the crutch, there are also short spherical hooks set on the side to meet the needs of the elderly to carry their belongings, which is safe and convenient. At the same time, the gravitational potential energy of the items can be directly converted into the power to flip the chair surface, which makes the operation more convenient and labor-saving.

NO.17 dimension change principle:It is to take crutch groove depression operation (linear one-dimensional) to replace the complicated $3 \mathrm{D}$ (three-dimensional) operation of turning the chair surface, which greatly reduces the difficulty and physical burden for the elderly to operate the flip chair surface. In addition, the armrests of the seats are arranged in a flat style to facilitate the elderly to help the elderly get up from the seats. (Figure 10) 


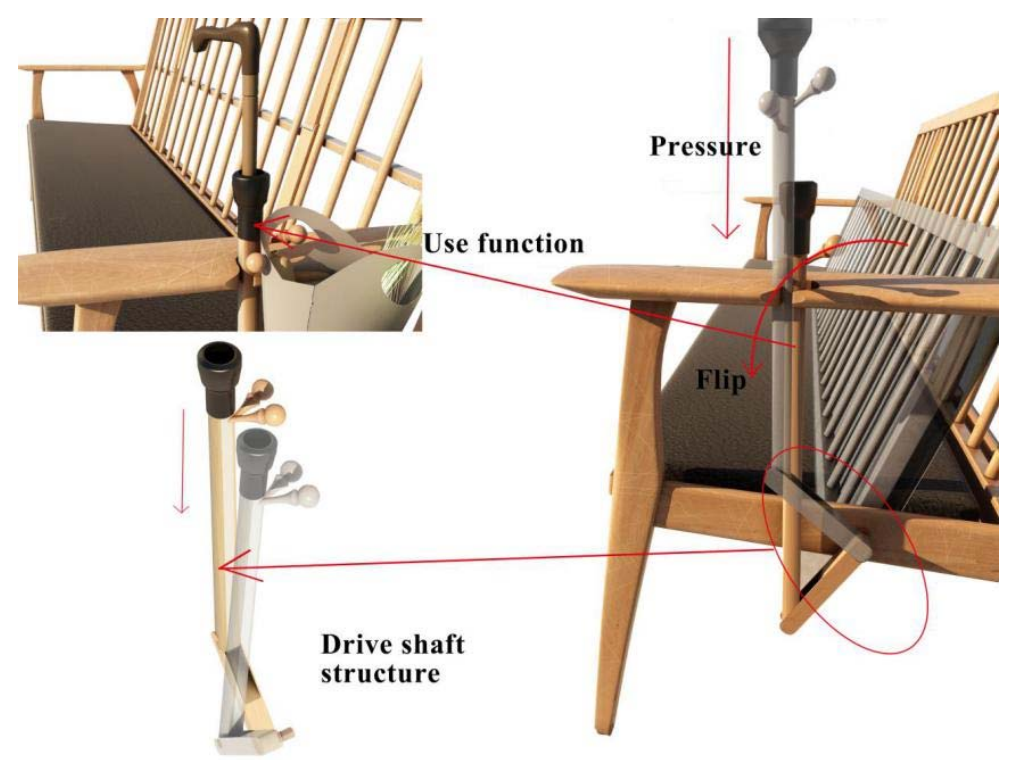

Figure 10. Operation design of suitable aging chair surface (Source: self-drawn by the author)

Contradiction No. 3: (Improvement parameter: adaptability or versatility; Deteriorated parameter: maintainability)The increase in the elderly-oriented function of the rest seat makes the maintenance and repair of the rest seat more difficult. the corresponding invention principles as NO.1, NO.16, NO.7, NO.4 can be obtained by Importing the conflicting general engineering parameters into the contradiction matrix. After analysis, it is found that NO.16 and NO.4 are less related to the problem, so the invention principles of NO.1 and NO.7 are used to solve the problems.

NO.1 Segmentation principle: Divide the parts that are easy to damage or difficult to repair and the main body of the rest seat into two parts, it is convenient to replace damaged parts and collect them for uniform maintenance during maintenance, which reduces the difficulty of maintenance.

NO.7 Nesting principle: Integrate the components of the flip system into a single component nested in the beam of the flip axis, which not only facilitates disassembly and maintenance but also protects the functional components and reduces the damage rate.

Contradiction number 4: This type of contradiction is physical contradiction. On the one hand, the chair surface cannot be immediately seated due to the slow movement of the elderly, if the chair surface rebounds immediately at this time, it may cause danger. Therefore, the chair surface needs to rebound slowly, that is, the resistance of the flip shaft needs to be increased to improve the viscosity of the flip system. But on the other hand, for easy and smooth operation, the resistance of the turning shaft should be as small as possible.

TRIZ theory provides four separation principles of time separation, space separation, local and overall separation for different functions require the same component to have two physical conflicts with opposite characteristics, while each separation method has several inventive methods corresponding to it. In view of the physical contradiction of the rest seat in the case, the condition separation principle is adopted to resolve the contradiction, that is, the damping is small when it is flipped to the use state, and the damping is automatically restored to the protection state. The corresponding invention principles are: $1,7,25,27,5,22,23,33,6,8$, $14,25,35,13$. After analysis, the principle 35 physical or chemical parameters changes can be used to solve this problem. That is to configure one-way damping at the rotating shaft to increase the friction force of the seat surface during the rotation and rebound process but not increase the friction force during the operation process.

Contradiction No. 5: This type of contradiction is a physical contradiction. Because the traction force of the seat surface rotating and rebounding is provided by the spring, it is necessary to overcome the traction force of the spring during the process of turning the seat surface, which becomes more and more laborious as the turning angle increases(Within the limit of tensile force, the tensile force of the spring increases with the elongation length), The elderly-oriented operation requires as little effort and even effort as possible, which requires that the spring tension is as small as possible to ensure that the required operating force in the second half of the process is not too large. In order to solve this physical contradiction, the condition separation principle combined with the No. 25 self-service principle in the corresponding invention principle are adopted to conduct the optimization. That is to increase the counterweight farther away from the center of rotation of the seat surface. During the operation with the rotation angle of the chair surface increases, the gravity arm becomes longer and longer too, at this time, the weight potential energy of the counterweight is continuously converted into a force that presses down the rotating seat surface, which counteracts the increasing spring tension to a certain extent, thereby The problem of uneven operation is overcome.

\subsection{Substance-Field analysis}

The substance-field analysis method is an important problem description and analysis method in TRIZ theory, 
which is used to construct a functional model that is related to the problems of existing systems and advanced technology systems. In the process of solving the problem, the corresponding general solution and standard solution can be found according to the problem described by the substance-field analysis model.[7] Compared with the contradiction analysis method used above, the substance-field analysis method is often more intuitive and more advantageous in solving functional requirements.

The substance-field analysis method was put forward by Altshuller, who put the theory in his book "Creation is Precision Science" in 1979, he believes that in any system, all functions can be decomposed into three basic elements: tool substance (S2), target substance (S1), field (F) (Figure 11).

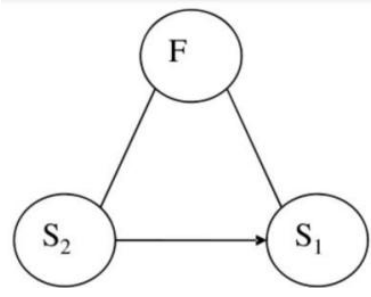

Figure 11. Basic substance-field model (Source: author's self-drawn)

The field (F) uses the tool substance (S2) as a carrier to affect the target substance. it can only achieve a complete cabinet function by maintaining the above three elements at the same time. Therefore, by analyzing the functional model composed of three elements, the completeness of function realization can be analyzed. In practical problems, substance-field analysis models can be divided into four categories. Except for effective complete models, the other three categories cannot fully implement system functions. it can be transformed into an effective complete model through the corresponding 6 general solutions. (Figure 12)

Model types
$\begin{gathered}\text { Effective complete } \\ \text { model }\end{gathered}$
$\begin{gathered}\text { Complete model with } \\ \text { insufficient effects } \\ \text { model }\end{gathered}$
$\begin{gathered}\text { Complete model } \\ \text { of harmful effects }\end{gathered}$

Figure 12. The substance-field model and the corresponding general solution

(Source: self-drawn by the author)

Problem analysis: At present, in the design of the rest seats in most elderly communities, there are only one-sided armrests on each side for users to use, which can not provide enough support for elderly people whose physiological functions are gradually degraded and who have difficulty on getting up, and which may even cause a fall due to an unstable center of gravity. It is necessary to conduct the elderly-oriented design of the rest seat armrest in the elderly community.

The substance-field analysis model is constructed for the above problems, The tool substance to assist the elderly to get up from the seat is the rest seat armrest, and the target substance is the elderly user, and there is also a field acting between the two, the force field formed by the force of the arms. (Figure 13) 


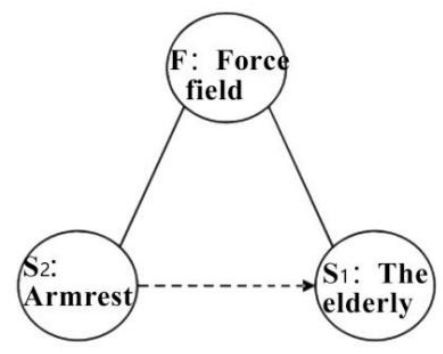

Figure 13. Getting up substance-field model (Source: author's self-drawn)

It can be seen from the analysis that this model type is "a complete model with insufficient effects", and the corresponding general solutions are NO.2, NO.3, and NO.4.
After exclusion, NO.3 can be used with adding another field S3 and another field F2 to strengthen the useful effect and NO.2 can be used with adding another field F2 to strengthen the useful effect and strengthen the system function.(Figure 14)

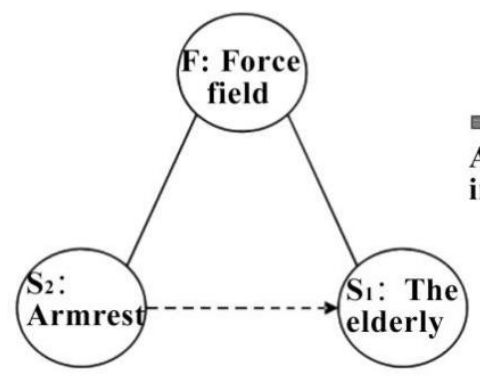

The Getting Up Substance-Field Model

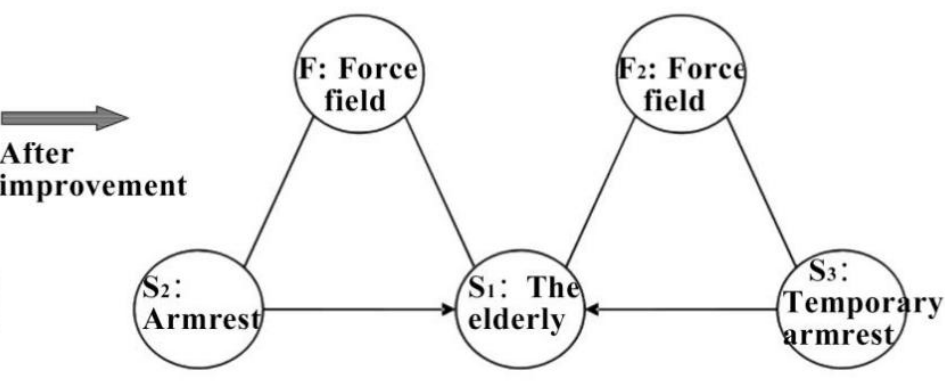

The Improved Getting Up

Substance-Field Model

Figure 14. The improved getting up substance-field model (Source: author's self-drawn)

It can be translated into an implementable solution:

(1)Add an armrest on both sides of the rest seat (S3 introducing), so that the elderly can support themselves with both hands to get up from the seat (force field F2 introducing, Figure 15).

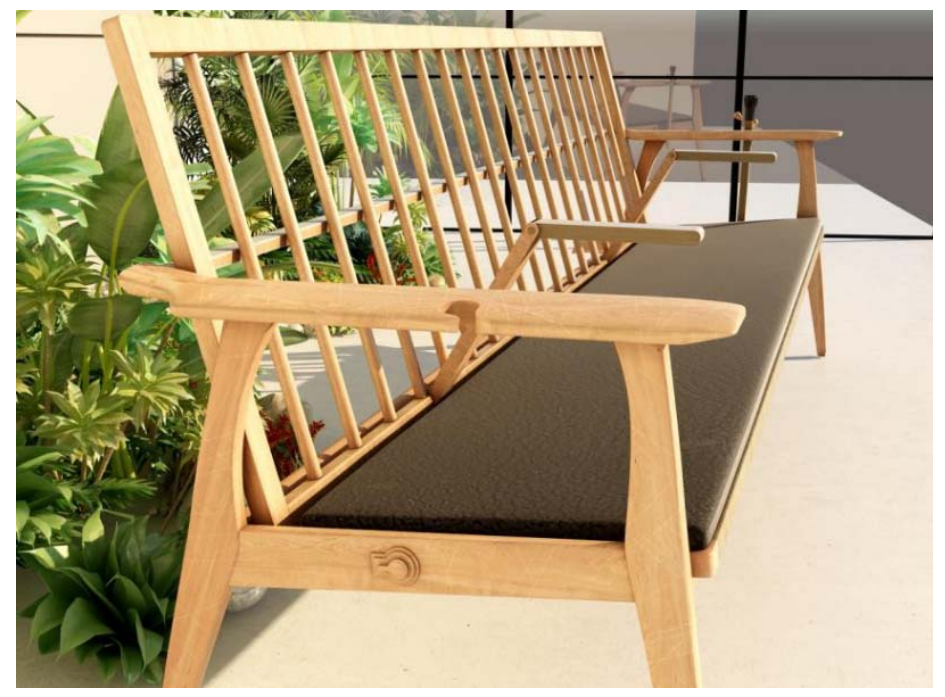

Figure 15. The scheme of adding armrests for elderly-oriented rest seats

(Source: self-drawn by the author)

(2) Set The armrest to a wide flat type to facilitate support for the elderly when they get up, that is, to increase the force fields F1 and F2 in the system.
In addition, since the newly added armrests are mainly for the elderly, while the sense of use of the rest seats is affected for most people. Therefore, in this case, 
the newly added armrest is foldable and nested in the backrest of the rest seat as a temporary armrest to provide assistance when the elderly get up. After it is pulled out for use Each time, it can be restored to its folded state following the rebound of the flip chair. The backrest is tilted back, the temporary armrests will remain folded back in the backrest due to the center of gravity when the seat surface is in use again, which can avoid affecting the use of most people. (Figure 16)

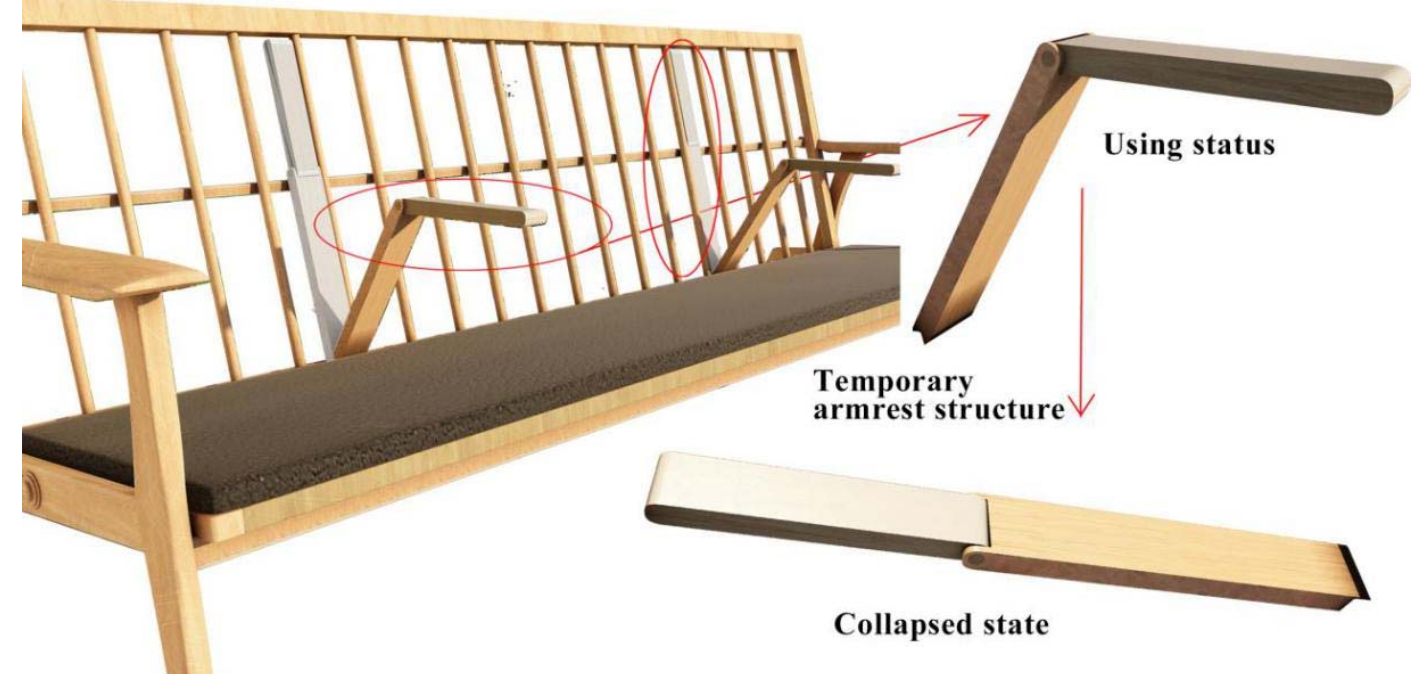

Figure 16. Design scheme of folding armrests for elderly-oriented rest seats rest seats

(Source: self-drawn by the author)

\section{Conclusion}

This article proposes an innovative design method and process based on the TRIZ theory, and proves its feasibility and effectiveness in design practice through the case of elderly-oriented transformation of outdoor rest seats in residential areas. As a scientific innovative design method, TRIZ theory is not only limited to technical disciplines, but also has a strong universality in the design field, and as the core of its creativity, the 40 invention principles are also very enlightening to the expansion of design ideas. In addition, TRIZ theory provides a large number of practical analysis tools for solving design problems, it analyzes and turns the actual problems encountered into TRIZ standard problems, The semantic mapping rate of this process directly determines the degree of design innovation and optimization, which can greatly shorten the time required for innovative design, break the mindset, and provide a more efficient and systematic innovation model for design.

\section{References}

1. Zhong G, Su W. (2019) Innovative Design of Growing Children's Solid Wood Chair Based on TRIZ Theory . Journal of Forestry Engineering, 2: 158-164.

2. ISAK ,B.(2016 ) TRIZ technology for Innovation. Science and Technology of China Press, Beijing.

3. Yao L. (2015) Research and Application of Product Innovation Design Based on TRIZ Theory. Guangdong University of Technology,Guangdong.

4. Xie L, Liu F, Guan Y.(2019) Research Progress of Home-based Pension Model in China. Qilu Nursing Journal, 15: 99-100.

5. Ren Shuo. (2016) Research on the Aging Configuration and Design of Home-based Pension and Leisure Space in Frigid Cold Area.Shenyang Jianzhu University, Shenyang.

6. Jiao X .(2014) Discussion on the Design of Outdoor Environmental Facilities of Elderly Apartments in Fuzhou . Fujian Agriculture and Forestry University ,Fujian.

7. Han Li.(2018) Research on Innovative Design of Preschool Children's Toys Based on TRIZ Theory. Xi'an University of Architecture and Technology, Xi'an. 